\title{
Family outcomes in early intervention: results from a nationwide study in Portugal
}

\section{Carina Sofia Correia Leite \& Ana Paula da Silva Pereira}

To cite this article: Carina Sofia Correia Leite \& Ana Paula da Silva Pereira (2019): Family outcomes in early intervention: results from a nationwide study in Portugal, Early Child Development and Care, DOI: 10.1080/03004430.2019.1585348

To link to this article: https://doi.org/10.1080/03004430.2019.1585348

曲 Published online: 01 Mar 2019.

Submit your article to this journal $₫$

View Crossmark data $\nearrow$ 


\title{
Family outcomes in early intervention: results from a nationwide study in Portugal
}

\author{
Carina Sofia Correia Leite ${ }^{a}$ and Ana Paula da Silva Pereira (1) ${ }^{b}$ \\ ${ }^{a}$ Research Center on Education (CIEd), Institute of Education, University of Minho, Portugal; ${ }^{b}$ Department of \\ Psychological of Education and Special Education, Research Center on Education (CIEd), Institute of Education, \\ University of Minho, Portugal
}

\begin{abstract}
Several studies have stressed the outcomes for families who are supported by Early Intervention in the following dimensions: knowledge/information; development of competencies; well-being; and quality of life. As a result, this study assessed 999 families to examine the outcomes of Early Intervention in Portugal. Our results show that families supported by Early Intervention benefit in dimensions related to the development of competencies in the child and the family, and to the gain of information and knowledge about support and community resources, which results in perceived control and co-responsibility. The analysis of the outcomes of Early Intervention also shows that parents' education and occupation levels are determining variables for a family to benefit from the positive impact of Early Intervention. In light of such results, we present recommendations for practices in the area of Early Intervention with the aim of adapting the practices of professionals to the concerns and priorities of Portuguese families.
\end{abstract}

\section{ARTICLE HISTORY}

Received 19 December 2018

Accepted 18 February 2019

\section{KEYWORDS}

Early Intervention; outcomes; families; children with special needs

Several studies present a set of outcomes perceived by families who are supported by Early Intervention (EI) in terms of knowledge and information, development of skills, well-being, and quality of life (Bailey, Hebbeler, Scarborough, Spiker, \& Mallik, 2004; Cossio, Pereira, \& Rodriguez, 2017, 2018; Dunst, 2002, 2015; Leite \& Pereira, 2013; Pereira \& Serrano, 2014).

Knowledge and information about Special Needs (SN), as well as access to community resources and services by parents, are a direct result of El, as referenced by Adler, Salanterä, Leino-Kilpi, and Grädel (2015), Coogle, Guerette, and Hanline (2013), and also, Cossio et al. (2017, 2018).

Another area considered by families as one of the outcomes of $\mathrm{El}$ is the development of parental skills in promoting learning, a healthy and balanced development of their children, and knowledge on how to deal with specific child behaviours. Families who have children with SN experience difficulties related to parental competences (Adler et al., 2015; Coogle et al., 2013) and, as a result, sometimes feel insecure about their ability to promote their children's development (Almeida et al., 2012). In this way, the ability of parents to understand the needs, development, and progress of their child is highly valued and a desired outcome in El (Dunst \& Bruder, 2002).

Families' well-being and quality of life are also reported by several authors as being a direct result of El (Bailey, Scarborough, Hebbeler, Spiker, \& Mallik, 2004; Bhopti, Brown, \& Lentin, 2016; Cossio, Pereira, \& Rodriguez, 2018; Kuhlthau et al., 2011; Kuo, Bird, \& Tilford, 2011; Warfield, Hauser-Cram, Krauss, Shonkoff, \& Upshur, 2000). 
Bailey, Scarborough, et al. (2004) also concluded that families feel that El professionals have helped them to take on a more positive perspective of their child's future with SN. This data is asserted by Bhopti et al. (2016), who state that El influences both the physical and psychological health of parents of children with SN.

Poston et al. (2003) point out the importance of valuing the expectations of families, with this being a critical factor in their perceived quality of life. At this level, families express the need for help to cope with the consequences of a lack of time and attention for themselves, as well as for other family members. These expectations are also valued by families in regard to the development of work skills and opportunities, in terms of training and employment, as far too often parents of children with SN need to reduce their number of hours of work, or even to become unemployed, in order to be able to take care of their child (Kuhlthau, Hill, Yucel, \& Perrin, 2005; Kuo et al., 2011).

Family cohesion, that is, the degree of emotional attachment that binds family members is also considered to be a benefit that emerges from El support at the level of the family's quality of life (Mackay, 2003; Mahoney \& Perales, 2005; Margalit \& Kleitman, 2006; Warfield et al., 2000). Indeed, Margalit and Kleitman (2006) ascertained that the degree of family cohesion is higher after one year of support from El. Warfield et al. (2000) report that families with a strong sense of cohesion have the potential to foster optimal developmental opportunities for their children, while Mackay (2003) further adds that families with a strong emotional attachment are better able to cope with potentially adverse factors, such as challenges and stress.

To have supporting relationships with other parents of children with SN is considered to influence the quality of life of families supported by El (Baum, 2004; Bitsika \& Sharpley, 2000; Edwards \& Gallagher, 2014; Kerr \& Mclntosh, 2000; Mackintosh, Myers, \& Goin-Kochel, 2005). According to Baum (2004), and to Bitsika and Sharpley (2000), parental support groups enable the reconstruction of emotional balance and stability, as well as the reduction of anxiety and depression in families supported by El. Moreover, families supported by El consider parental meetings important to obtain support and resources from the community (Edwards \& Gallagher, 2014; Mackintosh et al., 2005; Solomon, Pistrang, \& Barker, 2001).

Currently, in Portugal, there is a change underway in the organization and functioning of El teams, highlighted in the publication of the Decree-Law no. 281/2009, of 6 October, whose main objective is the creation of a National System of Early Childhood Intervention. Decree-Law no. 281/2009 further defines El as a set of integrated support measures centred on the child and family. Support is therefore intended for children up to six years old who have SN or who are at risk of developmental delays, as well as their families.

In Portugal, El is provided by a group of professionals in the areas of education, health, and social welfare, which together create the Local Early Intervention Team. The goals of Local Early Intervention Teams are to: a) identify children and families for National System of Early Childhood Intervention; b) ensure the monitoring of children and families that do not meet the eligibility criteria for El; c) prepare and execute the Individual El Plan; d) identify and streamline community resources; (e) ensure an appropriate transition process for each child to other educational programmes, services, or contexts; f) articulate the contexts and the professionals where the child is included.

The support provided by El is given by only one of the professionals who integrates the Local Early Intervention Team, who is called the case coordinator. This professional promotes the cohesion, cooperation, participation, satisfaction, and fluency of communication between the family and the Local Early Intervention Team professionals (King et al., 2009; Shelden \& Rush, 2001).

Therefore, Decree-Law no. 281/2009 compels us to search for answers about the outcomes of El for Portuguese families. As a result, the following research questions were defined:

Research Question 1: Do families consider receiving outcomes from El support?

Research Question 2: In what dimensions, knowledge/information; control/co-responsibility; and development of competencies in the child and in the family, families consider receiving outcomes from El support?

Research Question 2: Parents' education and occupation levels influence their perception of the outcomes of El? 


\section{Methods}

\section{Participants}

Participants were 999 families with children with SN who had been supported by Local Early Intervention Teams in Portugal, for at least six months, in the year 2015. Most of the participants were mothers $(81.2 \%)$, while $13.7 \%$ were fathers, $3.1 \%$ were grandparents, and $2.0 \%$ corresponded to other degrees of kinship (e.g. cousin, aunt, godmother, sister, legal guardian).

Regarding parents' educational level, three levels of schooling were considered, namely: primary to middle school (up to the 9th year of schooling), secondary education (from the 10th to the 12th year of schooling), and higher education.

The majority of fathers had a primary to middle school education (56.2\%), $25.1 \%$ had a secondary education, and $18.6 \%$ had a university degree.The majority of mothers had a primary to middle school education (44.6\%), 31.5\% had a secondary education, and $23.8 \%$ had a university degree.

Most fathers (41.3\%) had very low-level jobs, $21.5 \%$ had low-level jobs, $17.1 \%$ had high-level jobs, $3.3 \%$ had very high-level jobs, and $16.7 \%$ were unemployed. Most mothers (36.6\%) had very low-level jobs, $17.8 \%$ had low-level jobs, $16.9 \%$ had a high-level job, $4.1 \%$ had a very high-level job, and $24.5 \%$ were unemployed.

\section{Recruitment procedures}

Once the authorization from the National System of Early Childhood Intervention was obtained, Local Early Intervention Teams in Portugal were contacted. From the 144 teams contacted, only 65 agreed to collaborate. The professionals from the 65 Local Early Intervention Teams were then asked to submit questionnaires to the families, to be completed and placed in an envelope which they could easily seal, after having filled out the questionnaire. This procedure was carried out to safeguard the confidentiality of the participants. It was also requested that the questionnaire should be completed by only one family member. In total, 2493 questionnaires were sent out, and 1005 questionnaires were returned, for a rate of $40.3 \%$. Of the 1005 questionnaires received, six were excluded, since they only included responses referring to sociodemographic data. Thus, the sample of the present study consisted of 999 families of children with $\mathrm{SN}$, aged between six months and six years, in mainland Portugal. Data collection took place over 10 months.

\section{Data collection instrument}

The Early Intervention Benefits Identification Questionnaire for the Family (Leite \& Pereira, 2017), adapted from Harbin and Neal (2003), was used as a data collection tool. This questionnaire consists of two parts: Part 1 -Sociodemographic information; Part II - Identification Questionnaire of the Benefits of Early Intervention for the Family.

Part I - Sociodemographic Information. The first part of the questionnaire consists of: a) the parents' personal and socioeconomic details, namely their level of schooling and profession; b) personal factors of the child supported by El, namely age, gender, and type of SN; c) factors associated to the characterization of the support provided by Local Early Intervention Teams, particularly the overall El support time, the time of support provided by the case mediator, and the support context.

Part II - The Early Intervention Benefits Identification Questionnaire for the Family (Leite \& Pereira, 2017). This 22-item questionnaire has three dimensions: knowledge/information (four items); control/co-responsibility (eight items); and development of competencies in the child and in the family (10 items). Items cover a set of benefits: knowledge about the child's condition, such as 'Knowing our child's difficulties, delays, or special needs'; support relationships between family members, friends, and professionals, such as 'Having, if you wish, a relationship of help with another family that has children with special needs similar to those of our child'; inclusion and participation 
in the community, such as 'Participating with our child in community activities' as a result of participation in El. Responses were provided on a 6 point Likert scale (ranging from $1=$ often disagree to $6=$ strongly agree). Cronbach's alpha for these 22 items was .90 .

\section{Data analysis procedures}

The descriptive analysis method was used to analyze the average household's perception about the outcomes of El support taking into account the three dimensions under analysis ((Research Question 1). The One-way ANOVA was used to identify significant differences in outcomes taking into account independent variables such as parents' education and occupation levels (Research Question 2).

\section{Results}

Results will be presented according to the three research questions asked:

\section{Do families consider receiving outcomes from El support?}

Regarding the analysis of the different items of the questionnaire, there is variance of averages between 4.10 and 5.60, and a total mean of 4.92 ( $4=$ I sometimes agree, $5=$ I often agree).

The items with the highest average are, respectively and in descending order, item 5 - 'Facilitate and promote the development of our child' (5.60); item 12 - 'Identify the strengths, needs, and progress of our child' (5.42); item 1 - 'Understanding the difficulties, delays, or special needs of our child' (5.40), and item 15 - 'Feeling hopeful and optimistic about our child's future' (5.39).

The items with the lowest average are, respectively and in ascending order, item 17 - 'Having, if you wish, a helping relationship with another family ...' (4.10); item 21 - 'Participating in the organizations/associations that exist in our community... ' (4.10), item 19 - 'Finding someone to take care of or stay with our child.' (4.14), and item 22 - 'Participating in activities which can improve the support for children with special needs ...' (4.24).

From the analysis of the mean values obtained, families do consider to receive outcomes from El support. These outcomes are more evident in the dimensions of competence development in the child and family $(M=5.26)$, and knowledge/information $(M=5.19)$, when compared to the mean values obtained in the control/co-responsibility dimension $(M=4.37)$ (see Table 1$)$.

\section{Parents' education and occupation levels influence their perception about the outcomes of El?}

In order to accurately analyze this question, we have regrouped parents' education levels, considering the higher level of one of the parents, as defined by Machado et al. (2003).Therefore, the three levels of schooling followed in Portugal (primary to middle school, secondary education, and higher education) were considered.

From the analysis of Table 2, there are no statistically significant differences in the knowledge/ information dimension, taking into account the defined levels of education $(p=.089)$. Also, there

Table 1. Distribution of items in three dimensions.

\begin{tabular}{lcccr}
\hline & $N$ & Min-Máx & Mean & DP \\
\hline Knowledge / Information & 999 & $1-6$ & 5.19 & .87 \\
Control / Coresponsibility & 999 & $1-6$ & 4.37 & 1.27 \\
Development Competencies & 999 & $1-6$ & 5.26 & .80 \\
Total & 999 & & & \\
\hline
\end{tabular}


Table 2. Differences in the three dimensions of benefits according to parents' educational level.

\begin{tabular}{|c|c|c|c|c|c|c|c|c|}
\hline & Education level of parents & $N$ & Mín-Máx & Mean & DP & $F$ & $\mathrm{Gl}$ & Sig. \\
\hline \multirow[t]{4}{*}{ Knowledge Information } & Primary to middle school & 394 & $1-6$ & 5.21 & .92 & & & \\
\hline & Secondary & 333 & $2-6$ & 5.24 & .79 & & & \\
\hline & Higher & 272 & $1-6$ & 5.09 & .88 & & & \\
\hline & Total & 999 & $1-6$ & 5.19 & .87 & 2.420 & 998 & .089 \\
\hline \multirow[t]{4}{*}{ Control / Coresponsibility } & Primary to middle school & 394 & $1-6$ & 4.54 & 1.19 & & & \\
\hline & Secondary & 333 & $1-6$ & 4.47 & 1.20 & & & \\
\hline & Higher & 272 & $1-6$ & 4.01 & 1.38 & & & \\
\hline & Total & 999 & $1-6$ & 4.37 & 1.27 & 16.036 & 998 & .000 \\
\hline Bonferroni & \multicolumn{8}{|c|}{ Primary to middle school $>$ Higher* Secondary $>$ Higher* } \\
\hline \multirow[t]{4}{*}{ Development competencies } & Primary to middle school & 394 & $1-6$ & 5.29 & .81 & & & \\
\hline & Secondary & 333 & $1-6$ & 5.35 & .68 & & & \\
\hline & Higher & 272 & $2-6$ & 5.11 & .88 & & & \\
\hline & Total & 999 & $1-6$ & 5.26 & .80 & 7.426 & 998 & .001 \\
\hline Bonferroni & \multicolumn{8}{|c|}{ Primary to middle school $>$ Higher* Secondary $>$ Higher* } \\
\hline
\end{tabular}

${ }^{*} p \leq .05$.

was no differentiation in the mean values in the three groups of schooling defined (primary to middle school, secondary education, and higher education). However, only in the dimensions control/coresponsibility $(p=.000)$, and development of competences $(p=.001)$, were there statistically significant differences.

The Bonferroni test was used to determine the existence of contrasts between the three groups of schooling in the factors control/co-responsibility and development of competences. Statistically significant differences were found between families with primary to middle school and secondary education, when compared to families with a higher education level.

Regarding the occupation of the father and mother, three levels were considered (low, mediumlow, medium-high, and high), according to the designation adopted in psychological studies and education in Portugal. Level 1 - Low occupation level: construction workers; housekeepers; rural workers, or fishery workers; Level 2 - Low occupation level: Drivers, hairdressers, or public service employees; Level 3 - High and very high occupation level: teachers, nurses, tradesmen, doctors, lawyers, senior state and business officials, or businessmen.

We regrouped the parents' occupations, having considered the highest profession level of one of the parents, as recommended by Machado et al. (2003).

From the analysis of Table 3, there are statistically significant differences in the perceptions of the families about the outcomes of El, according to the three factors: knowledge/information $(p=.036)$, control/co-responsibility $(p=.000)$, and development of competencies $(p=.001)$, taking into account the parents' occupation.

Table 3. Differences in the three dimensions of benefits according to parents' ocupation.

\begin{tabular}{|c|c|c|c|c|c|c|c|c|}
\hline & Parents' Ocupation & $N$ & Mín-Máx & Mean & DP & $F$ & $\mathrm{Gl}$ & Sig. \\
\hline \multirow[t]{4}{*}{ Knowledge/Information } & Low level & 352 & $1-6$ & 5.26 & .88 & & & \\
\hline & Medium low level & 300 & $1-6$ & 5.20 & .88 & & & \\
\hline & Medium high and high levels & 347 & $1-6$ & 5.10 & .84 & & & \\
\hline & Total & 999 & $1-6$ & 5.19 & .87 & 3.346 & 998 & .036 \\
\hline Bonferroni & \multicolumn{8}{|c|}{ Low level $>$ medium high and high levels* } \\
\hline \multirow[t]{4}{*}{ Control/Coresponsibility } & Low level & 352 & $1-6$ & 4.62 & 1.16 & & & \\
\hline & Medium low level & 300 & $1-6$ & 4.46 & 1.16 & & & \\
\hline & Medium high and high levels & 347 & $1-6$ & 4.04 & 1.38 & & & \\
\hline & Total & 999 & $1-6$ & 4.37 & 1.27 & 19.719 & 998 & .000 \\
\hline Bonferroni & \multicolumn{8}{|c|}{ Low level > medium low level and high* Medium low level $>$ Medium high and high levels* } \\
\hline \multirow[t]{4}{*}{ Development of competencies } & Low level & 352 & $1-6$ & 5.36 & .79 & & & \\
\hline & Medium low level & 300 & $1-6$ & 5.30 & .73 & & & \\
\hline & Medium high and high levels & 347 & $2-6$ & 5.13 & .84 & & & \\
\hline & Total & 999 & $1-6$ & 5.26 & .80 & 7.583 & 998 & .001 \\
\hline Bonferroni & \multicolumn{8}{|c|}{ Low level > medium low level and high* Medium low level $>$ Medium high and high levels* } \\
\hline
\end{tabular}


The Bonferroni test was used to determine the existence of a contrast between the three occupation levels in the three factors. As a result, it was possible to verify that there are statistically significant differences between families with a low occupation level and families with medium-high and high occupation levels in concern to the knowledge/information factor. Also, there are statistically significant differences between families with a low and medium-low occupation level, and families with a medium-high and high occupation level, in the control/co-responsibility and in the competence development factors.

\section{Discussion}

The results obtained in this study show that families perceive to obtain outcomes when they are supported by El in the dimensions related to the development of competences in the child and the family, to a gain of information and knowledge about existing community support and resources, and to a sense of control/co-responsibility of the family in the El process.

The analysis of the outcomes of El also demonstrated that parents' level of schooling and employment may work as decisive variables in the attainment of outcomes for the families. These results are supported and explained by some studies by several authors (Bailey, Hebbeler, et al., 2004; Dunst, Hamby, \& Brookfield, 2007a; Dunst, Leet, \& Trivette, 1988; Leite \& Pereira, 2013; Sampaio \& Geraldes, 2006; Warfield et al., 2000).

More specifically, with regard to parents' level of schooling, we found that families with primary to middle school and secondary education present higher values regarding the outcomes of El in the dimension of child and family competency development, in comparison with parents with higher education levels. These results are similar to those obtained by Kirby, White, and Baranek (2015), and by Leite and Pereira (2013). It is possible to ground these results on the ease of access to information by parents with a higher level of schooling outside the El support system (Bailey, Hebbeler, et al., 2004; Gowen, Christy, \& Sparling, 1993). On the other hand, families with a primary to middle school or secondary level of schooling show more difficulties in getting involved within their communities, which translates into fewer opportunities for access to information (Bailey, Blasco, \& Simeonsson, 1992; Boushey, Brocht, Gundersen, \& Bernstein, 2001; Dunst et al., 1988; Park, Turnbull, \& Turnbull, 2002).

Regarding the variable parents' job, our results show that families with a low and medium-low level jobs present higher values regarding their perceptions about the outcomes of El, in the dimensions of competence development in the child and in the family, knowledge/information, and control/co-responsibility, when compared to families with high and medium-high professions. These results may suggest that families with a higher level job tend to evaluate practices as being less family-centered (Dunst, Hamby, et al., 2007a), resulting in a decrease of the perceived outcomes of El. However, these results contradict the results obtained in several research studies that refer to the absence of statistically significant differences in the variable parents' job (Epley, Summers, \& Turnbull, 2011; Mackintosh et al., 2005; McWilliam, Tocci, Sideris, \& Harbin, 1998; Mohammed Nawi, Ismail, \& Abdullah, 2013; Olmsted et al., 2010).

\section{Limitations and future research}

The first limitation of this study is the use of a questionnaire as a data collection instrument. Although the questionnaire method is recommended by the Early Childhood Outcomes Center (Bailey, Bruder, \& Hebbeler, 2006), it presents some disadvantages, since it does not allow the researcher to delve deeply into what families think about the outcomes of El. To obtain a clearer interpretation of the data obtained, we consider that an interview or focus group could be appropriate methods to seek further clarification and interpretation of the data.

Secondly, the results reflect only the perspectives of one of the family members, namely the mother of the child supported by El. Future studies should consider other elements of the 
family, such as both parents, in order to obtain different points of view about this phenomenon.

\section{Implications for practice}

Our results show that families considered obtaining outcomes from being supported by El. Thus, these data contribute to highlight the importance of El in the lives of families, thus stressing the need to hire professionals with specific training in the area of El in Portugal, so that they can, in a more consistent and qualified way, apply the best practices for El, namely the family-centered approach, transdisciplinarity, and support in the natural contexts (Division for Early Childhood, 2014). Such data may also help professionals to tailor their practices to the specific needs, priorities, and individuality of the supported families (Dunst, Trivette, \& Hamby, 2007). Furthermore, the results of this study can also promote a more effective knowledge on behalf of the families regarding the role of El and its scope when responding to their concerns and priorities.

\section{Acknowledgements}

This work is funded by CIEd - Research Centre on Education, projects UID/CED/1661/2013 and UID/CED/1661/2016, Institute of Education, University of Minho, through national funds of FCT/MCTES-PT.

\section{Disclosure statement}

No potential conflict of interest was reported by the authors.

\section{Funding}

This work is funded by CIEd - Research Centre on Education, projects [grant number UID/CED/1661/2013 and UID/CED/ 1661/2016], Institute of Education, University of Minho, through national funds of FCT/MCTES-PT.

\section{Notes on contributors}

Carina Sofia Correia Leite is Speech Therapist with PhD in Special Education at the University of Minho.

Ana Paula da Silva Pereira, Assistant Professor at the Department of Psychology of Education and Special Education and she develops her research work in Education on Research Center, of the Institute of Education, University of Minho, Portugal. She is coordinator of Early Intervention Master course. She acts in the field of special needs with strong scientific interests in the areas of Autism Spectrum Disorder, Family Centered Practices in Early Intervention, and Authentic Assessment in Early Intervention.

\section{ORCID}

Ana Paula da Silva Pereira (iD) http://orcid.org/0000-0003-4611-7602

\section{References}

Adler, K., Salanterä, S., Leino-Kilpi, H., \& Grädel, B. (2015). An integrated literature review of the knowledge needs of parents with children with special health care needs and of instruments to assess these needs. Infants \& Young Children, 28(1), 46-71. doi:10.1097/IYC.0000000000000028

Almeida, A., Abreu-Lima, I., Cruz, O., Gaspar, M. F., Brandão, T., Alarcão, M., ... Machado, J. C. (2012). Parent education interventions: Results from a national studyin Portugal. European Journal of Developmental Psychology, 9(1), $135-149$. doi:10.1080/17405629.2011.647865

Bailey, D. B., Blasco, P. M., \& Simeonsson, R. J. (1992). Needs expressed by mothers and fathers of young children with disabilities. American Journal of Mental Retardation, 97(1), 1-10.

Bailey, D., Bruder, M. B., \& Hebbeler, K. (2006). Guidance for states in documenting family outcomes for early intervention and early childhood special education. Menlo Park: Early Childhood Outcomes Center. 
Bailey, D. B., Hebbeler, K., Scarborough, A., Spiker, D., \& Mallik, S. (2004). First experiences with early intervention: A national perspective. Pediatrics, 113(4), 887-896. doi:10.1542/peds.113.4.887

Bailey, D., Scarborough, A., Hebbeler, K., Spiker, D., \& Mallik, S. (2004). Nationalearly intervention longitudinal study: Family outcomes at the end of early intervention (Report No. 6). Menlo Park: SRI International.

Baum, L. S. (2004). Internet parent support groups for primary caregivers of a child with special health care needs. Pediatric Nursing Journal, 30(5), 381-401.

Bhopti, A., Brown, T., \& Lentin, P. (2016). Family quality of life: A keyoutcome in early childhood intervention services - A scoping review. Journal of Early Intervention, 38(4), 191-211. doi:10.1177/1053815116673182

Bitsika, V., \& Sharpley, C. (2000). Development and testing of the effects of support groups on the well-being of parents of children with autism-II: Specific stress management techniques. Journal of Applied Health Behaviour, 2(1), 8-15.

Boushey, H., Brocht, C., Gundersen, B., \& Bernstein, J. (2001). Hardships in America:The real story of working families [Adobe Digital Editions version]. Retrieved from http://www.epinet.org/books/hardships.pdf

Coogle, C. G., Guerette, A. R., \& Hanline, M. F. (2013). Early intervention experiences of families of children with an autism spectrum disorder: A qualitative pilot study. Early Childhood Research \& Practice, 15(1). Retrieved from http://ecrp.uiuc. edu/v15n1/coogle.html

Cossio, A. P., Pereira, A. P. S., \& Rodriguez, R. C. C. (2017). Benefícios e nível de participação na intervenção precoce: Perspectivas de mães de crianças com perturbação do espetro do autismo [Benefitsanddegreeofparticipation in earlyintervention: Perspectivesofmothersofchildrenwithautismspectrumdisorder]. Revista Brasileira de Educação Especial, 23(4), 505-516. doi:10.1590/S1413-65382317000400003

Cossio, A. P., Pereira, A. P. S., \& Rodriguez, R. C. C. (2018). Benefícios da intervenção precoce para a família de crianças com transtorno do espectro do autismo [Benefitsofearlyintervention to thefamiliesofchildrenwithautismspectrumdisorder]. Revista Educação Especial, 31(60), 9-20. doi:10.5902/1984686X28331

Decrew-law n. ${ }^{\circ}$ 281/2009. (2009). Sistema Nacional de Intervenção Precoce na Infância [NationalSystemofEarlyIntervention in Childhood]. Diário da República, I Série. N. 193 (09-10-06), 7298-7301.

Division for EarlyChildhood. (2014). DEC recommended practices in early intervention/early childhood special education 2014. Retrieved from http://www.dec-sped.org/recommendedpractices

Dunst, C. J. (2002). Family-centered practices: Birth through high school. The Journal of Special Education, 36(3), 141-149. doi:10.1177/00224669020360030401

Dunst, C. J. (2015). Professional-family help giving relationships in family support programs. International Journal OfCase Studies, 4(9), 23-31.

Dunst, C. J., \& Bruder, M. B. (2002). Valued outcomes of service coordination, early intervention, and natural environments. Exceptional Children, 68, 361-375. doi:10.1177/001440290206800305

Dunst, C. J., Hamby, D. W., \& Brookfield, J. (2007). Modeling the effects or early childhood intervention variables on parent and family well-being. Journal of Applied Quantitative Methods, 3(2), 268-288.

Dunst, C. J., Leet, H. E., \& Trivette, C. M. (1988). Family resources, personal well-being, and early intervention. The Journal of Special Education, 22(1), 108-116. doi:10.1177/002246698802200112

Dunst, C. J., Trivette, C. M., \& Hamby, D. W. (2007). Meta-analysis of family-centered helpgiving practices research. Mental Retardation and Developmental Disabilities Research Reviews, 13, 370-378. doi:10.1002/mrdd.20176

Edwards, N., \& Gallagher, P. A. (2014). Parent educators in early intervention: Insights from evaluations. Infants \& Young Children, 27(3), 220-240. doi:10.1097/IYC.0000000000000011

Epley, P. H., Summers, J. A., \& Turnbull, A. P. (2011). Family outcomes of early intervention: Families' perceptions of need, services, and outcomes. Journal of Early Intervention, 33(3), 201-219. doi:10.1177/1053815111425929

Gowen, J. W., Christy, D. S., \& Sparling, J. (1993). Informational needs of parents of young children with special needs. Journal of Early Intervention, 17, 194-210. doi:10.1177/105381519301700209

Harbin, G., \& Neal, P. (2003). Family benefits inventory (Unpublished instrument). North Carolinaat Chapel Hill, FPG Child Development Institute.

Kerr, S. M., \& McIntosh, J. B. (2000). Coping when a child has a disability: Exploring the impact of parent-to-parent support. Child: Care, Health and Development, 26(4), 309-322. doi:10.1046/j.1365-2214.2000.00149.x

King, G., Strachan, D., Tucker, M., Duwyn, B., Desserud, S., \& Shillington, M. (2009). The application of a transdisciplinary model for early intervention services. Infants \& Young Children, 22(3), 211-223. doi:10.1097/IYC.0b013e3181abe1c3

Kirby, A. V., White, T. J., \& Baranek, G. T. (2015). Caregiver strain and sensory feature in children with autism spectrum disorder and other developmental disabilities. American Journal on Intellectual and Developmental Disabilities, 120 (1), 32-45. doi:10.1352/1944-7558-120.1.32

Kuhlthau, K. A., Bloom, S., Van Cleave, J., Knapp, A. A., Romm, D., Klatka, K., ... Perrin, J. M. (2011). Evidence for family-centered care for children with special health care needs: A systematic review. Academic Pediatrics, 11(2), 136-143.e8. doi:10.1016/j.acap.2010.12.014

Kuhlthau, K., Hill, K. S., Yucel, R., \& Perrin, J. M. (2005). Financial burden for families of children with special health care needs. Maternal and Child Health Journal, 9(2), 207-218. doi:10.1007/s10995-005-4870-x

Kuo, D. Z., Bird, T. M., \& Tilford, J. M. (2011). Associations of family-centered care with health care outcomes for children with special health care needs. Maternal and Child Health Journal, 15(6), 794-805. doi:10.1007/s10995-010-0648-x 
Leite, C. S. C., \& Pereira, A. P. S. (2013). Early intervention in Portugal: Family support and benefits. Support for Learning, 28, 146-153. doi:10.1111/1467-9604.12034

Leite, C. S. C., \& Pereira, A. P. S. (2017). The early intervention benefits identification questionnaire for the family. Braga, Portugal: Universidade do Minho.

Machado, F. L., Costa, A. F., Mauritti, R., Martins, S. C., Casanova, J. L., \& Almeida, J. F. (2003). Classes sociais e estudantes universitários: Origens, oportunidades e orientações [Social classandcollegestudents: Origins, opportunities, andguidelines]. RevistaCrítica de CiênciasSociais, 66, 45-80.

Mackay, R. (2003). Family resilience and good child outcomes: An overview of the research literature. Social Policy Journal of New Zealand, 20, 98-118.

Mackintosh, V. H., Myers, B. J., \& Goin-Kochel, R. P. (2005). Sources of information and support used by parents of children with autism spectrum disorders. Journal of Developmental Disabilities, 12(1), 41-51.

Mahoney, G., \& Perales, F. (2005). Relationship-focused early intervention with children with pervasive developmental disorders and other disabilities: A comparative study. Journal of Developmental and Behavioral Pediatrics, 26(2), 7785. doi:10.1097/00004703-200504000-00002

Margalit, M., \& Kleitman, T. (2006). Mothers' stress, resilience and early intervention. European Journal of Special Needs Education, 21(3), 269-283. doi:10.1080/08856250600810682

McWilliam, R. A., Tocci, L., Sideris, J., \& Harbin, G. (1998). Using and providing services: Case studies in early intervention (Report No. 141). North Carolina: Early Childhood Research Institute on Service Utilization.

Mohammed Nawi, A., Ismail, A., \& Abdullah, S. (2013). The impact on family among Down syndrome children with early intervention. Iranian Journal of Public Health, 42(9), 996-1006.

Olmsted, M. G., Bailey, D. B., Raspa, M., Nelson, R. E., Robinson, N. D., Simpson, M. E., \& Guillen, C. (2010). Outcomes reported by Spanish-speaking families in early intervention. Topics in Early Childhood Special Education, 30(1), 4655. doi:10.1177/0271121409360827

Park, J., Turnbull, A., \& Turnbull, H. R. (2002). Impacts of poverty on quality of life in families of children with disabilities. Exceptional Children, 68(2), 151-170. doi:10.1177/001440290206800201

Pereira, A. P. S., \& Serrano, A. M. (2014). Early intervention in Portugal: Study of professionals' perceptions. Journal of Family Social Work, 17(3), 263-282. doi:10.1080/10522158.2013.865426

Poston, D., Turnbull, A., Park, J., Mannan, H., Marquis, J., \& Wang, M. (2003). Family quality of life: A qualitative inquiry. Mental Retardation, 41(5), 313-328. doi:10.1352/0047-6765(2003)41313:FQOLAQ>2.0.CO;2

Sampaio, F. M., \& Geraldes, S. (2006). Necessidades das famílias de crianças comdeficiência: Um estudo com aescalaFamily Needs Survey [The needs of families with children with disorders: A study with the Family Needs Survey]. Revista da Faculdade deCiências Humanas e Sociais do Porto, 3, 277-287.

Shelden, M. L., \& Rush, D. D. (2001). The ten myths about providing early intervention services in natural environments. Infants \& Young Children, 14(1), 1-13. doi:10.1097/00001163-200114010-00004

Solomon, M., Pistrang, N., \& Barker, C. (2001). The benefits of mutual support groups for parents of children with disabilities. American Journal of Community Psychology, 29(1), 113-132. doi:10.1023/A:1005253514140

Warfield, M. E., Hauser-Cram, P., Krauss, M. W., Shonkoff, J. P., \& Upshur, C. C. (2000). The effect of early intervention services on maternal well-being. Early Education and Development, 11(4), 499-517. doi:10.1207/s15566935eed1104_8 